\title{
Doubt and Guilty: A Theoretical and Clinical Study on the Identificatory Problem in an Obsessional Neurosis Case
}

\author{
Henrique Guilherme Scatolin \\ PUC-SP (Pontificate Catholic University of São Paulo), São Paulo, Brazil
}

\begin{abstract}
This study, which is still in progress, sought to investigate the identificatory problem in an obsessional neurosis case. For this purpose, it sought to build analysis tests from four central pillars: the Oedipal resolution of the patient Paulo parents, his libidinal and identificatory story, the incorporation of sadistic penis, and the superego identification. This study methodology is based on the Freudian psychoanalytic theory on the obsessions and in post-Freudian psychoanalysts' readings on this neurosis, such as Green and Bleichmar. Over the results, the floating theorizing was built, focusing on his stories and associations. Therefore, after hearing Paulo story, it was possible to understand the parents desire since his birth, emphasizing how the paternal function, beside the maternal, was present, always, in his psychological construction. Through the primary scene construction the possible existing triangulation was highlighted since its primary function, giving subsidies to understand Paulo's first ambivalent movements, his Oedipus complex, and how these movements are intertwined to his identificatory building. Throughout these discussions, it was pointed out that a great part of his destructive impulses were thrown out during his rituals, although a small part of these would be merged, feeding the resistance, his paralysations, his uncertainties, and his guilt in the clinical setting, denoting that, in his identificatory problem, his debt to his father was of his own desire order. This study concluded that the four central pillars are of extreme relevance to the obsessive identificatory problem elucidation, becoming interchangeable in the data analysis from each obsessive patient unique story.
\end{abstract}

Keywords: superego identification, sadistic penis, sadistic-anal phase

\section{Introduction}

The construction of this thesis, which is still in progress, consists of a theoretical and clinical study on the identificatory problem in obsessional neurosis. For this purpose, it resorts the guilty unconscious feeling and the doubt of an obsessive patient, unveiling them as an anchor point for this problem understanding.

The present study about this problem is the result of the author's clinical observations of patients who the author considers obsessive neurotic. During these patients psychotherapeutic treatment, it was noticed that the identificatory problem understanding was of fundamental importance for the understanding of the unconscious feeling of guilty, since it highlighted the symbolic "debt" with the father. This means that this identification revealed the ambivalence in the father-son relationship, which is fundamental in understanding this neurosis and its symptoms.

It is highlighted that this idea of "symbolic debt" comes from the author's singular reading of the text "debt

Henrique Guilherme Scatolin, Master, PUC-SP (Pontificate Catholic University of São Paulo). 
and guilty", of Calligaris (1991), in which the author states that, in the relationship of the obsessive with his father, "It means to create an inspector, more specifically to call a creditor to verify that the debt is being paid (the study is due to the father, and receive a carnal tribute to his superiority” (1991, p. 21). Due to the existence of a hard superego, that comes as an inspector, the author notes that many obsessive patients nourish a relationship of ambivalence regarding the father, and this is made explicit in his obsessive symptoms, such as in doubts and in certain obsessive rituals. It is highlighted that, in certain cases, this ambivalence relationship is directly linked to the identification with the father, being the (un)conscious guilty feeling a result of this identificatory problem.

In addition, the interest in the study of this identificatory problem in obsessional neurosis is present since the time the author finished his master's degree, in 2007, when the author defended the dissertation entitled $A$ Theoretical Clinical Study on the Ceremonial Act in Obsessional Neurosis. In this research, the author emphasized that the ritual to hide knives represented for the psychic constitution of an obsessive patient. During the ritual, this patient great fear (or desire) was being anally penetrated by knives. Thus, this clinical case analysis, which the author named The Knives Man, opened the first doors for future questions on this issue, being the understanding of Bleichmar (1993) on the incorporation of paternal phantasmagorical sadistic penis of paramount importance to understand the father-son identificatory relationship and the homosexuality ghosts, such as passivity, that open from this anal incorporation.

So, this indication of Bleichmar (1993) also made me wonder about Paulo identificatory problem, arousing the author to a reflection on this subject. This means that in the author's clinic listening and, from the patient associations, the author noticed that the presence of a paternal identification made it possible to understand how the doubt symptom and the guilty unconscious feeling were put to Paulo. And, in the author's clinical experience with Paulo and other obsessive patients, the author understands that the passivity ghosts (from the father's penis anal incorporation) become strengthened by the libidinal regression to the sadistic-anal phase, delighting all the obsessive identificatory problem through doubts (in which people find the ambivalent impulses to the parents), and guilty, in which the incestuous desire regarding the mother and the aggressive impulses toward the father pay the due price.

Thus, this work aims to focus on the relevance of the identificatory problem for understanding the guilty unconscious feeling and the doubt in this neurosis. For this study, the author chose a patient who he believes is obsessive neurotic, and whose understanding of a possible libidinal and identificatory story denotes this ambivalence relation towards the father. This patient, who the author identifies with the fictitious name of Paulo, seeks psychotherapy due to the ruminant thoughts of his father death (and his father had died two years ago), and also complained a lot of chest pains.

For this case presentation, the author will emphasize the therapeutic process occurred since the patient Paulo arrival until his fourth year of psychotherapy. The author highlights that in this cutting he find sufficient data for the development of this thesis proposal, i.e., the careful study of the identificatory problem is the guiding axis for understanding the guilty and doubt in the obsessional neurosis cases.

Therefore, for this study, the author will be supported by the possible libidinal and identificatory story of patient Paulo, pointing out though his stories, dreams and dissimulating memories, how this problem is manifested in his doubts and his guilty feeling.

\section{Methodology}

This study on the identificatory problem in obsessional neurosis is based on psychoanalysis as a theory, 
therapeutic technique, and investigation method of the unconscious. In this study, the texts written by Sigmund Freud on the obsessional neurosis occupy a key position. To these the author adds the theoretical contributions of Piera Aulagnier for the Freudian meta-psychology and psychopathology, since the author believes that these provide and understanding of the identificatory problem in this neurosis. Despite this psychoanalyst has not addressed specifically the obsessional neurosis, there are fundamental concepts of her theory that enrich the understanding of the psychic constitution of this research subject.

As the author understands the analytical process as "Something that you live every day, session after session...” (Pontalis, 2002), the annotations from this case occurred shortly after the session ending, respecting the uniqueness and the free associations of this patient.

According to Mezan (1993), "The psychoanalytic literature contains numerous examples and elaborations that serve as a working too.... These are schemas to correlate data, to infer hypothesis, to suggest derivations". The author highlights that his working tools are based on his psychoanalytic reading of Freudian work, the Piera Aulagnier contributions to it, as well as the postulates of Andre Green and Bleichmar on the obsessional neurosis. Thus, it was possible to develop a sustenance building that provided the author the support for the study of this problem, enabling the development of the floating theorizing of this clinical case.

These theorizing based on psychoanalytic theory and technique, since this research is of qualitative character and is based on the data analysis of the libidinal and identificatory story of only one patient. This research field had as object Paulo psychic reality and all manifestations of his unconscious. The method used was the data interpretation from their free associations, but also the possibility conditions for the empirical emergence of his unconscious formation.

\section{Results and Discussion}

Listening to the reports of death thoughts of this patient, the author realized that, in these, the identification with the father revealed a lack, a guilty, in which his ideals were never achieved. It was "in this lack" that, on one hand it was a son complaining about a (dis)pleasure of his symptoms and, on the other, a father that, although dead, reigned in the imagination as if he were still alive, permeating this patient dreams and symptoms. Consequently, Paulo guilty charged its price for the debt with the father, making the doubt a symptomatic manifestation of his ambivalent impulses.

On the other hand, in the study of this problem, Paulo's mother had a key role. During the psychotherapeutic process, this became almost "untouchable" in his verbalizations, but over his stories, the "father" was giving way to the mother. So, the way the mother recognizes the paternal function, the father law, and how it was passed on to the son is a priceless wealth in this case analysis. This means that, for a better understanding of Paulo identificatory problem the presence of this mother is also of extreme importance. And, from the reports of dreams in which the mother figure was present, the author developed certain "floating theorizing" (Aulagnier, 1989), which allowed me to suppose how this mother recognizes the paternal function and how the presence of this "rude" father interdicted Paulo infant desires, leading him to pay a high price for wanting what could not have been desired: the incest and the patricide.

And for deepening on this theory postulate, the author would like to come back to the four guiding axis of this problematic, intertwining them with Paulo clinical data, as well as other cases of obsessional neurosis already serviced by me.

The first axes for this problem understanding is supported on the Oedipal resolution of these patients' 
parents, and which in this study refers, specifically, to the case of Paulo. For this purpose, the author resorts to the concept of spoken-shadow, since this is directed to the maternal repressed and the spokeswoman notion.

For Aulagnier (1975), "These relations analysis (spokeswoman, infant body, and the repressing action) will allow the elucidation of this identificatory problem, which has the axis of transmission, subject to subject, of a repressed necessary to the structural requirements of myself” (p. 60). In the case of Paulo, as well as other obsessive patients, the maternal repressed guarded an enormous wealth, since in this it was possible to detect the recognition of a third representative that would mediate the law between the child and the maternal relationship.

This is the paternal function, the father law, already present, since always, in the repressed of Angela and this acknowledged in her husband Claudio the only representative that could legitimize and transmit this law to Paulo. Remember that when making allusion to Paulo father presence in his cemetery dream, this mother pointed out the presence of a third reference. So, Angela (Paulo's mother) recognized in Claudio the paternal function that once her own father passed on her remote childhood. It is remembered here an old statement by Claudio that symbolically is directed to the parents' desire for this son: his father, in his birth, had to choose between the mother and his life. The answer was clear: The father wanted the two alive of nothing. So, the father wish, the paternal function, was present, since always, side by side with the desire and the maternal function, libidinally investing the small Paulo and enabling the first incorporations that nurtured his identifications since the early childhood.

At this point, the reader might be wondering how this repressed can be transmitted to the obsessive patient. Here the author would like to bring a second axis of identificatory problem: the superego identification in obsessions, postulated by Green (1967), in his article "Obsessional neurosis metapsychology", in 1967. It is believed that it is through this identification that the maternal and paternal repressed, the moral values and judgments are transmitted from generation to generation, providing a fresh look to the guilty.

For starting this discussion, first, the author would like to use the New Introductory Lectures on Psychoanalysis, when Freud (1933/1996) says that the superego installation can be classified as a successful example of the parental instance identification, since a child superego does not follow her parents' model, but her parents' superego, enabling the values transmission between the generations. In this clinical case, it is supposed that in this process the guilty covers its price for the small Paulo. When internalizing the parents' values in his superego, the father debt, permeated by the unconscious guilty, already finds its origin in the story of Claudio with the father, which name was never mentioned, as well as in the story of Paulo with the father Claudio. Here opens a dubious dilemma: both in his story and in the story of the father, through the identifications, the guilty charges its price. In other words, there is identification to the father, which myth permeates the two generations in this family: the myth of the "died" father, who still reigns very much alive in this patient family imagination, permeating, also, his funeral rituals.

In addition, it was noticed that his hard superego identification was driving his moral judgments, so striking in his story, as well as in his father Claudio story. And by denying that he did not want to be like his father, Paulo reassumed the identificatory position with him, repeating many demanding behaviors that his own father had in his childhood, although with more controlling contours due to his infantile sadism sublimations.

Still in this second axis, something caught the author's attention for the understanding of his guilties and uncertainties. If the superego identification reports him to previous generation, feeding his guilty, the author 
finds a quote in Green (2005), that launches a new understanding on the uncertainty manifestation, when he says: "the doubt towards the father, the obsessive reiterates it expecting to annul it, borrowing from the father's father, to whom the latter remains debtor” (p. 227). So, when resorting to the grandfather, whose name was never mentioned, Paulo tries to deceive the movement of his own desire, once that, while staying on the prowl of his fantasies, he waits to delete any trace of a debt that one day he contracted from his own father Claudio, allowing, in his imagination, a free way for the enjoyment of a desired object, but that, due to the presence of this hard superego identification, was never consummated. And here opens the thresholds of his defense mechanisms, providing high doses of (dis)pleasure to his ego, that confronting with his overwhelming superego, develops an unconscious guilty that paralyzed him so much due to his destructive impulses.

At this point, the author would like to turn to the third axis of the identificatory problem proposed by this thesis: Paulo libidinal and identificatory story, because a brief resumption of this throws new looks for the ambivalence that guided this patient uncertainties in the clinical setting.

In order to accomplish this articulation, the author would like to remind that the "I", throughout the story, was constructed through indentificatory dialectic. In this dialectic, it is found that the "three successive times, represented by primary identification..., specular identification... and project identification” (Aulagnier, 1968). Paulo ambivalence, present behind his doubts, resplended the remnants of the demand object relations, present in his pre-genital identification. Currently, the old faeces sacrifice gives room for other ambivalent manifestations; such as avarice, denoting other outlines of his ambivalent movements that are behind his libidinal and identificatory story.

If, at the end of the oral phase, both the father and the mother already moved his ambivalences (remember the primary scene and the speculate identification, such active (sadistic) and passive movements (coming from his anal eroticism)) are intensified in the sadistic-anaphase, determining the ambivalence in relation to the male and female representatives in his adult genital organization. And through his manifestations of time and people control, it is believed that the sadistic movement has overlapped to the anal eroticism in his remote childhood, with this latter related to the passivity and the masochism that really paralyzed him, holding, partially, his uncertainties and guilty in his adulthood. Thus, both the passivity and the masochism had its roots in Paulo's old anal eroticism, making the anal constipation and his constipations a slight hysterical trait of his symptomatic manifestation.

And from the understanding of this libidinal and identificatory story, the author would like to turn to this thesis fourth and final pillar (or axis): the incorporation of the paternal sadistic penis, proposed by Bleichmar (1993). The author would like to remember the trunk in the cemetery dream: when being crossed, cornered, by the paternal sadistic penis, Paulo woke up "distressed”, with constipated intestines and ran to the bathroom to "relieve" the "constipated" anger to the father, since this castration agent represented the cut in the relationship with his mother. So, in order to internalize this penis, Paulo anally introjected the aggressiveness and the hate projected to Claudio, and this displeasure reported in the dream refers, in the author's understanding, to the old pleasure of this incorporation, which founded the passive movements of his anal eroticism, feeding the old homosexual desire and, strengthening, with this incorporation, the sadistic aspects of his superego.

This means that, in this psychic instance, this inspector mentioned by Calligaris (1991), are present in the sadistic impulses towards the father's body (remember the primary scene of trucks), which were anally 
incorporated with this paternal attribute, allowing the male sexual identification to Claudio. In addition, in the remnants of this incorporation that are presents in the passivity ghosts that still persisted behind his masochism and his unconscious feeling of guilty, creating obstacles to his cure and encouraging his therapeutic setting resistance.

There is still something in the cemetery dream that needs to be explained. When reporting the dream in which he looked at the mother and she directed her look to the father, appearing the trunk that, in his association, would be the cemetery tree, the author understood that on incorporation of this sadistic penis rested the beginning of his guilty, because by incorporating his father law, the incestuous desire would pay its price.

Here was the dilemma of this patient: Every time when his identification anxiety (or castration) arose in the setting, he needed to resume the former identificatory position towards Claudio, taking, symbolically, the stick and going fishing. At this moment, as the author was saying, it was God and him in this fact, in the author's understanding, it promoted his guilty. And in this guilty intricacies, his ambivalences are intensified, because, once the penis is incorporated, it caused him, symbolically, a coming and going of his obsessive thoughts, such as the old anal penis in the middle of his intestine, providing a masturbatory pleasure in view of his uncertainties.

And for a better understanding of how this incorporation of paternal attribute reflects in this patient identificatory problem, the author would like to mention, briefly, the three times of Oedipus proposed by Lacan.

According to this psychoanalyst, in the first time, there is "the relation of the child... with the mother desire” (Lacan, 1957-1958, p. 208). At this point, Paulo held a privileged place as being the maternal phallus, denoting a merger to maternal omnipotence.

In the second time, we have "the moment when the father is felt as the prohibitory. He appears in the mother speech” (Lacan, 1957-1958, p. 209). If, at first, Angela maternal speech was captured in a raw state, at this second time, the father's speech appears mediated, but not fully unveiled in Angela maternal speech. We should also remember his gaze pointing to a third reference in the cemetery, and when little Paul turns, symbolically, he faces Claudio.

This oneiric memory can be correlated to the third moment of his Oedipus complex, in which "the father enters the game... as the one who has it. He intervenes at this level to provide what is at the cause of the phallic deprivation. It appears, effectively, in the donation act” (Lacan, 1957-1958), namely the phallus donation, law representative, so present in Paulo moralistic speech.

In the author's understanding, from this third time lies Paulo obsessive problem. When moving from the position of being the maternal phallus to the position of having his father phallus incorporated, through the trunk that cornered him, Paulo incorporates the moral laws and judgments of his micro social environment. These values will guide his ideal egojudgments, feeding, in the future, his guilties.

Therefore, the sadistic penis incorporation opens the intricacies of this patient identificatory problem, positioning in front of this castration problem, since that having the phallus means the possibility of losing it. This fact drives the decline of his Oedipus complex, leading him to identify his heir: and his hard, sadistic and moralist superego. This superego identification in Aulagnier understanding corresponds to the symbolic identification, culminating in the identification to Paulo identificatory project. For this reason, he always demanded to be the best father, the best seller, and the best friend. 
And as the identificatory project corresponds to the ego ideal in the Freudian theory, the author understands that when Green refers to the superego identification as an obsessive problem, he believes that this problem would correspond to the symbolic identification that would culminate with the intensification of internal demands present in the identificatory projects of my obsessive patients, denoting a conflict between the author and his ideals and ensuring, thus, a demanding content meant for themselves. So, this symbolic identification understanding, proposed by Aulagnier, reinforces the assumption proposed by Green for understanding this issue in obsessions.

Before finalizing this article, the author would like to elucidate one last issue. Many might be wondering if there is an order of these four axes for the elucidation of an obsessive problem. It is highlighted that these four axis proposed for the obsessive problem elucidation are interchangeable, i.e., there is no correct sequence or hierarchy, but no axis can be ignored, since all four are of extreme relevance to the understanding of this obsessive problem, guiding the clinical look of the future analyst when this comes across an obsession case in his office.

\section{Conclusion}

The author's clinical experience with Paulo and other obsessive patients, as well as the principles of Freud (about obsessional neurosis), of Aulagnier (regarding the identificatory dialect in "I" constitution), of Bleichmar (in relation to the incorporation of the father penis ghost), of Calligaris (which intertwines the doubt and the guilty in relation to the debt that the obsessive nourished towards the father), and of Green (in which he highlights the superego identification) allow the author to propose that only by means of a detailed analysis of the identificatory problem, which occurs since the childhood (and the ambivalent relations in the sadistic-anal phase), is when we can understand how each obsessive patient feels regarding the guilty and "debt" with the father figure, because the author considers the debt, the guilty and, consequently, the symbolic debt with the father, the structural engine of this psychopathology.

Therefore, this article postulates that the identificatory problem is the guiding axis for the understanding of the unconscious guilty and the doubt feelings in the obsessional neurosis. For this purpose, four fundamental points are highlighted in understanding this problem: the Oedipal father and mother resolution of each obsessive patient (here including the maternal repressed transmission), the libidinal and identificatory story understanding for these patients "I" constitution, the anal incorporation of paternal sadistic penis (being the ghosts from this incorporation reinforced by the sadistic-anal regression) and the identificatory process with the father figure since the beginning of psychic constitution (culminating with the superego identification). These four points are of extreme importance for the understanding of this problem that underlies the doubt and guilty symptoms, guiding the obsessive patients' analysis and the study problem proposed in this research.

\section{References}

Aulagnier, P. (1968/1990). A performer's search for meaning-I. Sao Paulo: Escuta.

Aulagnier, P. (1975). A violência da interpretação-Do pictogramaaoenunciado (The violence of interpretation-From pictogram to statement). Rio de Janeiro: Imago.

Aulagnier, P. (1984/1989). The historian apprentice and wizard master. São Paulo: Escuta.

Bleichmar, S. (1993). Nas Origens do Sujeito Psíquico: do mito a história (In the psychic subject origins: From myth to history). Porto Alegre: ArtesMédicas. 
Calligaris, C. (1991). Dívida e culpa (Debt and guilt). In A Cura. Associação Psicanalítica de Porto Alegre, 5.

Freud, S. (1933/1996). Novas Conferências Introdutórias Sobre a Psicanálise (New introductory lectures on psychoanalysis). Rio de Janeiro: Imago.

Green, A. (1967/2005). Metapsicologia da Neurose Obsessiva (Obsessional neurosis metapsychology). In Obsessiva Neurose. Manoel Tosta Berlinck (org). São Paulo: Escuta.

Lacan, J. (1957-1958/1999). O Seminário 05: As Formações do Inconsciente. (The seminar 05: The unconscious formations). Rio de Janeiro: Jorge Zahar.

Mezan, R. (1993). Quesignifica “pesquisa” empsicanálise? (What means "research” in psychoanalysis?) In SILVA, Maria EmíliaLino da (coord). Investigação e Psicanálise. Campinas: Papirus.

Mijolla, A. (2005). DicionárioInternacional da Psicanálise (International psychoanalysis dictionary). Rio de Janeiro: Imago.

Pontalis, J. B. (2002). Jornal de Psicanálise (Psychoanalysis journal). São Paulo.

Ribeiro, M. A. C. (2003). A Neurose Obsessiva (The obsessional neurosis). Rio de Janeiro: Jorge Zahar. 